\title{
Hepatic Abnormalities Associated with Aluminum Loading in Piglets
}

\author{
Gordon l. Klein, Aileen B. Sedman, Melvin B. Heyman, Gopal Marathe. Hector A. Battifora, \\ Jack L. Worrall, Ronald L. Horst, George J. Brewer, Nancy L. Miller. and Allex C. Alfrey
}

From the Divisions of Pediatrics and Pathology, City of Hope National Medical Center, Duarte, California: Departments of Pediatrics and Medicine, University of Michigan Medical Center, Ann Arbor, Michigan; Department of Pediatrics, Lnicersity of California Medical Center, San Francisco, California; Center for Electron Microscopy and Microanalysis, University of Southern California, Los Angeles, California; Medical and Research Services, VA Medical Center and University of Colorado School of Medicine, Denver, Colorado; and the L.S.D.A. National Animal Disease Center, Ames, Iowa

\begin{abstract}
Cholestasis is a common complication of total parenteral nutrition (TPN) in infants. A contributing factor to the hepatic dysfunction may be a contaminant of the TPN solution, such as aluminum, that accumulates in liver and may act as a hepatotoxin. To study the hepatic effects of aluminum, growing piglets were given daily intravenous injections of aluminum, $1.5 \mathrm{mg} / \mathrm{kg}$, for 50 days; pair-fed controls were given heparinized saline. At sacrifice, liver and serum were obtained. Liver was analyzed for histopathology and for aluminum content and localization. The hepatocyte lysosomes of the experimental group showed aluminum peaks by $\mathbf{x}$-ray microanalysis, whereas the control group did not. No differences in ultrastructure were noted between the two groups when examined by
\end{abstract}

electron microscopy. Mean serum total bile acid levels $(27.8 \pm$ $15.9 \mathrm{SD}$ os $6.3 \pm 1.5 \mu \mathrm{mol} /$ liter, $p<0.05)$. mean alkaline phosphatase $(309 \pm 108$ vs $180 \pm 27$ IU/liter, $p=N S)$, and mean hepatic copper content $(24.8 \pm 4.5$ is $14.4 \pm \mu \mathrm{g} / \mathrm{g}$ dry weight, $p<0.01$ ), were elevated in the aluminum-loaded piglets, indicating that cholestasis may have been produced. Also, a small but significant reduction in serum levels of 25 hydroxyvitamin $\mathrm{D}$ was found in the aluminum-loaded piglets, suggesting that vitamin $D$ hydroxylation may be impaired. Inasmuch as lysosomal contents are excreted into the bile, aluminum accumulation in lysosomes may alter lysosomal function and possibly affect bile flow or content. (Journal of Parenteral and Enteral Nutrition 11:293-297, 1987)
Cholestasis and progressive liver disease are common complications of treatment with prolonged total parenteral nutrition (TPN), especially in infants and young children. ${ }^{1-4}$ The etiology of the hepatic dysfunction is unclear and may be multifactorial. One possibility is that a component of TPN solution may act as a hepatotoxin. ${ }^{1}$

Aluminum has recently been identified as a contaminant of TPN solutions. ${ }^{5}$ It was initially found in the casein hydrolysate used as the protein source, ${ }^{5}$ and, subsequently, has been identified in calcium ${ }^{6}$ and phosphate ${ }^{6,7}$ salts, heparin, ${ }^{6}$ and albumin. ${ }^{6,8}$ It is also known to be a contaminant of some solutions used in hemodialysis. ${ }^{9}$ Its accumulation in bone ${ }^{9 \cdot 11}$ and brain ${ }^{12.13}$ has been linked to disease in those tissues. Infants and children treated with TPN for several months or years may accumulate significant quantities of aluminum in the liver. ${ }^{14}$ They may also develop rickets responsive only to large doses of vitamin D..$^{15}$

This pilot study was designed to determine whether hepatic aluminum accumulation could contribute to the pathogenesis of cholestasis or to alterations in vitamin D metabolism.

\section{METHODS}

\section{Animals}

Eight piglets (Amo Farms, Ann Arbor. MI). 6 weeks old, were studied. Piglets were selected because the study

Received for publication, April 7, 1986.

Accepted for publication, September 4. 1986.

Reprint requests: Dr. Gordon L. Klein. Department of Pediatrics, University of Texas Medical Branch. Galveston. Texas 77550. of aluminum bone toxicity in lower animals, such as rats, has not consistently produced changes closely analogous to human bone disease. ${ }^{16}$ The piglets were divided into experimental and control groups of four each. Starting weights of the piglets in the experimental group were 9.7 \pm 2.1 (SD) kg, range 8.2-12.8; starting weights for the control group were $9.2 \pm 1.6 \mathrm{~kg}$, range 8-11.4. Each underwent left external jugular venous catheterization following general anesthesia with $1.5 \mathrm{~g}$ ketamine, $0.4 \mathrm{mg}$ atropine, halothane, and nitrous oxide. The Tigon catheter was tunnelled under the skin and brought out onto the back. Its patency was maintained by twice daily flushing with 1-2 ml of heparinized saline.

The four experimental animals were given a daily intravenous bolus injection of $1.5 \mathrm{mg} / \mathrm{kg}$ of elemental aluminum as aluminum chloride (MCB Reagents, Darmstadt, West Germany) for 50 days. This dose of aluminum was selected as being large enough to produce changes in renal function in dogs. ${ }^{17}$

Bolus injection was chosen over continuous int ravenous infusion of aluminum because both long-term TPN and hemodialysis treatments are given periodically, rather than continuously; thus, aluminum administration as a contaminant of those solutions is periodic. The four controls were given an equivalent volume of heparinized saline over the same time period. Both groups of animals were pair-fed a diet of Purina Pig Growena Chow $T 20$ during the course of the -tudy.

At the conclusion of the study period, the piglets were fasted for $12 \mathrm{hr}$ and then were killed by intravenous administration of a lethal dose of sodium pentobarbital. Sections from the right lobe of the liver were then obtained in aluminum-free containers ${ }^{14}$ for ultrastruc- 
tural examination and aluminum and copper quantification; aliquots of serum were also obtained in plastic containers for quantitative aluminum, copper. total bile acids, alkaline phosphatase, and $25(\mathrm{OH})$ vitamin D $[25(\mathrm{OH}) \mathrm{D}]$ determinations.

\section{Tissue Preparation}

Tissue submitted for electron microscopy was cut into 1 - $\mathrm{mm}$ cubes and fixed in a mixture of $2 \%$ paraformaldehyde and $2.5 \%$ glutaraldehyde in casodylate buffer for 1 hr. It was then washed in phosphate buffer $(\mathrm{pH} 7.3)$ and fixed in $1 \%$ osmium tetroxide in the same buffer for 1 hr. Each specimen then was washed several times with phosphate buffer, dehydrated in graded alcohol, and embedded in Spurr low-viscosity embedding medium. Ultrathin sections were cut on a LKB ultratome III, counterstained with uranyl acetate and lead citrate, and observed under a Phillips EM 301 electron microscope at an acceleration voltage of $80 \mathrm{kV} .^{18}$

\section{$X$-ray Microanalysis}

Blocks of piglet hepatic tissue $0.3 \mu \mathrm{m}$ thick and not fixed in osmium were mounted on copper grids and analyzed for the presence of aluminum. Despite the lack of osmium fixation in these particular samples, it was determined that organelle resolution was adequate to proceed with microanalysis. ${ }^{19}$ All samples were stained with lead citrate and uranyl acetate.

For microanalysis, a Phillips $420 \mathrm{~T}$ scanning transmission electron microscope (STEM) was used in conjunction with an Edax energy dispersive $\mathrm{x}$-ray spectrometer controlled by Tracor Northern TN-2000 automation. Analysis was performed in the STEM mode of operation; a low background sample holder was employed.

This apparatus is capable of detecting all elements of atomic number greater than sodium by means of characteristic $\mathrm{x}$-ray emission resulting from electron beam bombardment of a region defined by the beam, which can be focused to a diameter as small as $2 \mathrm{~nm}$. The accelerating voltage used was $80 \mathrm{kV}$, and the beam cur- rent intensity was approximately $0.5 \mathrm{nA}$. All areas of visualized hepatocytes were scanned by the electron beam, and characteristic $\mathrm{x}$-ray emission spectra for aluminum were recorded, wherever detectable, as peaks on a computerized tracing.

A Tracor software background fitting and subtraction program (+CS) was applied to the peaks to enhance spectral display. Peaks from the aluminum-loaded piglets and their pair-fed controls were displayed in such a way as to compare the curves in the pertinent regions.

\section{Biochemical Determinations}

Quantitative determinations of aluminum and copper in liver and serum were carried out by atomic absorption spectroscopy as previously described. ${ }^{20,21}$

Total serum bile acid concentrations were determined fluorometrically by the Sterognost 3 alpha Flu $^{\mathrm{R}}$ enzymatic method (Nyegaard and Co., Diagnostics Division, Oslo, Norway. ${ }^{22,23}$ Serum alkaline phosphatase determinations were carried out by standard autoanalyzer techniques. Serum levels of $25(\mathrm{OH}) \mathrm{D}$ were determined by the competitive protein binding assay. ${ }^{24}$

Statistical analyses were carried out using the Wilcoxon rank-sum test and paired $t$-test where appropriate.

\section{RESULTS}

The final weights of the pair-fed animals were similar: $17.6 \pm 2.8$ (SD) $\mathrm{kg}$ for the experimental group and 17.9 $\pm 2.0 \mathrm{~kg}$ for the controls.

\section{Biochemical Analysis}

The biochemical effects of aluminum administration are shown in Table I. Aluminum loading in the experimental group of piglets resulted in hepatic and serum aluminum levels significantly greater than those for the control group.

Cholestasis, as manifested by markedly elevated serum total bile acid levels occurred in three of the four aluminum-loaded piglets $(p<0.05$ compared to controls by

TABLE I

Biochemical effects of aluminum administration

\begin{tabular}{|c|c|c|c|c|c|c|}
\hline \multirow[b]{2}{*}{ Group } & \multicolumn{2}{|c|}{ Aluminum } & \multirow{2}{*}{$\begin{array}{c}\text { Serum } \\
25(\mathrm{OH}) \mathrm{D} \\
(\mathrm{ng} / \mathrm{ml})\end{array}$} & \multirow{2}{*}{$\begin{array}{c}\text { Serum total } \\
\text { bile acids } \\
(\mu \mathrm{mol} / \mathrm{liter})\end{array}$} & \multicolumn{2}{|c|}{ Copper } \\
\hline & $\begin{array}{c}\text { Hepatic } \\
\text { (mg/kg dry wt) }\end{array}$ & $\begin{array}{c}\text { Serum } \\
(\mu \mathrm{g} / \text { liter })\end{array}$ & & & $\begin{array}{c}\text { Hepatic } \\
(\mu \mathrm{g} / \mathrm{g} \text { dry wt })\end{array}$ & $\begin{array}{l}\text { Plasma } \\
(\mu \mathrm{g} / \mathrm{d} \mathrm{l})\end{array}$ \\
\hline \multicolumn{7}{|l|}{ Experimental } \\
\hline Piglet 2 & 1269 & 7020 & 10.91 & 42.6 & 25.74 & 139 \\
\hline 4 & 1392 & 1684 & 9.69 & 5.6 & 24.56 & 162 \\
\hline 6 & 1944 & 5928 & 9.97 & 34.5 & 29.93 & \\
\hline 7 & 1438 & 2340 & 8.73 & 28.5 & 19.00 & 152 \\
\hline Mean $\pm \mathrm{SD}$ & $1511 \pm 298$ & $4243 \pm 2728$ & $9.8 \pm 0.9$ & $27.8 \pm 15.9$ & $24.8 \pm 4.5$ & $151 \pm 11.5$ \\
\hline \multicolumn{7}{|l|}{ Control } \\
\hline Piglet 1 & 0.5 & $<2$ & 13.91 & 5.3 & 12.52 & 124 \\
\hline 3 & 0.6 & $<2$ & 11.32 & 6.8 & 14.06 & 130 \\
\hline 5 & 0.3 & $<2$ & 10.17 & 8.1 & 15.58 & 164 \\
\hline 8 & 1.5 & $<2$ & 12.93 & 4.8 & 15.41 & 117 \\
\hline Mean $\pm \mathrm{SD}$ & $0.7 \pm 0.5$ & $<2$ & $12.1 \pm 1.6$ & $6.3 \pm 1.5$ & $14.4 \pm 1.4$ & $133.8 \pm 20.9$ \\
\hline $\begin{array}{l}p \text { (experimental } v s \\
\text { control) }\end{array}$ & $p<0.001$ & $p<0.001$ & $p=0.05$ & $p<0.05$ & $p<0.01$ & NS \\
\hline
\end{tabular}


Wilcoxon rank-sum). Mean serum alkaline phosphatase levels were higher in the aluminum-loaded group. $309 \pm$ 108 vs $180 \pm 27 \mathrm{IU} /$ liter, although the difference was not significant. The mean hepatic copper content was nearly 2 -fold greater $(p<0.01)$, and the mean serum $25(\mathrm{OH}) \mathrm{D}$ levels were lower $(p=0.05)$ in the aluminum-loaded piglets, compared to pair-fed controls.

\section{Ultrastructural Analysis}

On routine electron microscopic examination, no qualitative differences in hepatocyte glycogen deposition, organelle size, or shape were apparent between the two groups. Similarly, no differences in bile ductular width, patency, or number were seen. Neither bile pigment nor inflammatory changes were detected in either group.

\section{X-Ray Microanalysis}

Figure 1 shows x-ray emission peaks from a lysosome of an aluminum-loaded piglet hepatocyte and, for comparison, from a lysosome of a pair-fed control. Peaks for aluminum and phosphate are prominent in the lysosome of the hepatocyte from the aluminum-loaded piglet. Similar patterns were detected in the hepatocytes of the other three aluminum-loaded piglets. This suggests that aluminum may be found in the lysosomes of the hepatocytes in the experimental group. However, not all lysosomes within a given hepatocyte were shown to contain aluminum; neither was aluminum detected in every hepatocyte examined. No aluminum peaks were detected after scanning the entire grid in any of the controls.

\section{DISCUSSION}

Our data indicate that growing piglets receiving a chronic parenteral aluminum load accumulate large amounts of aluminum in the liver and blood. Since serum creatinine was not different between experimental and control groups, decreased renal function cannot explain the large discrepancy in aluminum content existing between the two groups. The small quantity of aluminum, less than $1 \mu \mathrm{g} /$ day, administered to controls with the heparinized saline clearly had no effect on hepatic or serum aluminum levels. Cholestasis manifested by elevated serum bile acids developed, despite continued enteral stimulation of bile flow by means of feeding.

The elevation of serum alkaline phosphatase levels and hepatic copper ${ }^{25}$ in the aluminum-loaded group are consistent with the observed cholestatic effect. However, because osteomalacia was also produced in these piglets ${ }^{26}$ it is not clear whether the alkaline phosphatase is primarily from liver or bone. The mechanism of the elevated serum bile acid levels is unknown. However, another trace element, manganese, can initiate cholestasis by affecting canalicular membrane structure and cellular microfilaments. ${ }^{27}$

The failure to detect ultrastructural histopathology suggests that the elevation of serum bile acids may precede or be independent of the appearance of other hepatic pathology, as has been suggested to occur in TPN-associated liver disease. ${ }^{28}$ It has also been shown in rabbits ${ }^{29}$ and rats ${ }^{30}$ that infusions of glucose and amino acid solutions can acutely decrease bile flow without altering hepatic histology.

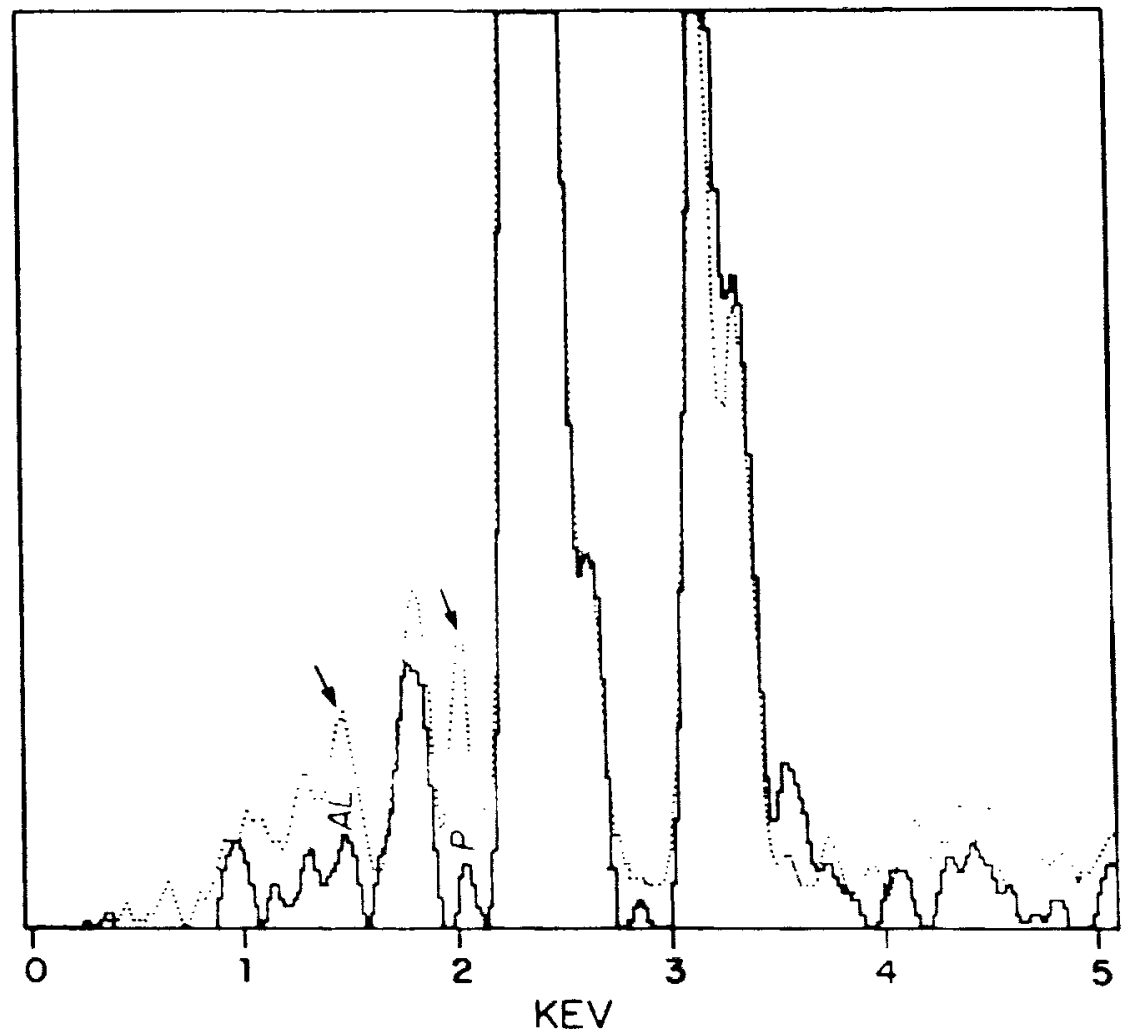

Fic. 1. Computerized tracings of element peaks from lysosomes of aluminum-loaded (broken line) and control (solid line) piglet hepatse". : i designate peaks for $A l$ and $P$ in the he- sosome of the aluminum-loaded piglet $\left(\mathrm{keV}^{\prime}=\right.$ thousand electron volts). 
It is unlikely that halothane anesthesia alone produced the cholestasis, since the control group also received halothane. Whether the halothane in some way predisposed the aluminum-loaded piglets to cholestasis cannot be determined at present.

Like most reagent grade crystals of this compound, the aluminum chloride crystals contain some lead; the lead content of the brand used was $5 \mathrm{ppm}$. Each piglet received an average of less than $1 \mu \mathrm{g} /$ day, an insignificant quantity in relation to the amount of aluminum given each day.

A previous report by Galle and Giudicelli ${ }^{31}$ described aluminum deposition in the fibrotic liver of a woman who had died of dialysis encephalopathy. However, the possibility of underlying chronic hepatic disease, such as non-A, non-B hepatitis, was not excluded. The same report describes changes in hepatocyte lysosomal size and shape in rats given chronic intraperitoneal injections of large doses of aluminum. However, no controls were used in the above-mentioned study, and our animals did not show these changes.

We can confirm the finding of aluminum in the lysosomes seen by Galle and Giudicelli, ${ }^{31}$ as well as by Verbueken et al. ${ }^{32}$ The significance of lysosomal aluminum accumulation is uncertain. However, since lysosomes may be a major route of biliary lipid excretion; the presence of aluminum may alter lysosome-to-bile excretion and contribute to an alteration of either bile composition or bile flow. ${ }^{33}$ Lysosomal aluminum accumulation may also represent a possible excretory route of aluminum from the liver via the bile ductules. However, the biliary route of aluminum excretion was shown to be insignificant in acutely loaded dogs ${ }^{34}$ as was enterostomal aluminum excretion in chronically loaded humans with normal renal function. ${ }^{35}$ In our study, the bile ducts of the piglets were not cannulated; thus, the contribution of this route to aluminum elimination, in the specific case of the chronically loaded piglet liver, cannot be determined.

The lower serum levels of $25(\mathrm{OH}) \mathrm{D}$ in the aluminumloaded piglets were still within the normal range ${ }^{36}$ However, since the half-life of $25(\mathrm{OH}) \mathrm{D}$ in the circulation, $2-4$ weeks, ${ }^{37}$ is long, changes in hepatic vitamin D 25hydroxylase activity may not be readily reflected in the circulating concentration of the sterol. However, the lower levels of $25(\mathrm{OH}) \mathrm{D}$ in the serum of the aluminumloaded piglets in consistent with the hypothesis that 25 hydroxylase activity may be decreased with aluminum loading. Data demonstrating a decrease in hepatic microsomal cytochrome P450 with aluminum loading in rats are also consistent with this hypothesis, ${ }^{38}$ as 25 -hydroxylation of vitamin $D$ in the liver is a cytochrome $\mathrm{P} 450$ dependent step.

Finally, the quantities of aluminum deposited in the livers of the experimental group of piglets are at least twice those found in patients with dialysis encephalopathy ${ }^{39}$ and at least 6 -fold greater than those found in chronically loaded infants receiving aluminumcontaminated TPN solutions. ${ }^{14}$ Thus, caution must be applied in extrapolating the results from our study to clinical situations. Further studies are necessary to determine whether these changes in liver function are still present when hepatic aluminum content is adjusted to the level seen in aluminum-loaded patients.

\section{ACKNOWLEDGMENTS}

This study was supported in part by U.S. Public Health Service Grant 15.1-973, by a grant from the John TungAmerican Cancer Society Nutrition Education Center, and by funds from the Veterans Administration. Valuable technical assistance was provided by Alina Fernandez, Hsein-Chen Tseng, and Robert Dick. Valuable secretarial assistance was provided by Peggy Berg, Pat Nichols, and Melody Wilkey. The authors would also like to thank John F. Rosen, M.D., for his helpful comments.

\section{REFERENCES}

1. Dahms BB, Halpin TC Jr: Serial liver biopsies in parenteral nutrition-associated cholestasis of early infancy. Gastroenterology 81:136-144, 1981

2. Postuma $R$, Trevenen CL: Liver disease in infants receiving total parenteral nutrition. Pediatrics 63:110-115, 1979

3. Touloukian RJ, Seashore JH: Hepatic secretory obstruction with total parenteral nutrition in the infant. J Pediatr Surg 10:353-360, 1975

4. Bernstein J, Chang $\mathrm{CH}$, Brough AJ, et al: Conjugated hyperbilirubinemia in infancy associated with parenteral alimentation. $J$ Pediatr 90:361-367, 1977

5. Klein GL, Alfrey AC, Miller NL, et al: Aluminum loading during total parenteral nutrition. Am J Clin Nutr 35:1425-1429, 1982

6. Sedman AB, Klein GL, Merritt RJ, et al: Evidence of aluminum loading in infants receiving intravenous therapy. N Engl J Med 312:1337-1343, 1985

7. de Vernejoul MC, Messing B, Modrowski D, et al: Multifactorial low remodeling bone disease during cyclic total parenteral nutrition. J Clin Endocrinol Metab 60:109-113, 1985

8. Milliner DE, Shinaberger JH, Shuman $P$, et al: Inadvertent aluminum administration during plasma exchange due to aluminum contamination of aluminum replacement solutions. N Engl J Med 312:165-167, 1985

9. Ott SM, Maloney NA, Coburn JW, et al: The prevalence of bone aluminum deposition in renal osteodystrophy and its relation to the response to calcitriol therapy. N Engl J Med 307:709-713, 1982

10. Ott SM, Maloney NA, Klein GL, et al: Aluminum is associated with low bone formation is patients receiving chronic parenteral nutrition. Ann Intern Med 98:910-914, 1983

11. Cournot-Witmer G, Zingraff J, Plachot JJ, et al: Aluminum localization in bone from hemodialyzed patients: Relationship to matrix mineralization. Kidney Int 20:375-385, 1981

12. Perl DP, Gajdusek DC, Garruto RM, et al: Intraneuronal aluminum accumulation in amyotrophic lateral sclerosis and Parkinsonismdementia of Guam. Science 217:1043-1055, 1982

13. Sedman AB, Wilkening GW, Warady BA, et al: Encephalopathy in childhood secondary to aluminum toxicity. J Pediatr 105:836838,1984

14. Klein GL, Berquist WE, Ament $M E$ et al: Hepatic aluminum accumulation in children on total parenteral nutrition. J Pediatr Gastroenterol Nutr 3:740-743, 1984

15. Klein GL, Cannon RA, Diament $M$, et al: Infantile vitamin Dresistant rickets associated with total parenteral nutrition. Am J Dis Child 135:74-76, 1982

16. Alfrey AC: Aluminum. Adv Clin Chem 23:69-91, 1983

17. Henry DA, Goodman WG, Nudelman RK, et al: Parenteral aluminum administration in the dog. I. Plasma kinetics, tissue distribution, and effects on calcium metabolism and parathyroid hormone. Kidney Int 25:362-369, 1984

18. Dawes CJ: Biological Techniques in Electron Microscopy. Barnes \& Noble, New York, 1971, pp 17-105

19. Lefevre R, Cournot-Witmer G: Electron microprobe analysis and analytical ion microscopy of normal and pathological bone (dialysis osteomalacia). Electron Microsc 3:106-107, 1980 
20. LeGendre GR, Alfrey AC: Measuring picogram amounts of aluminum in biological tissue by flameless atomic absorption analysis of a chelate. Clin Chem 22:53-56. 1976

21. Hill GM, Miller ER, Whetter PA: Concentration of minerals in tissues of pigs from dams fed different levels of dietary zinc. J Animal Sci 57:130-138, 1983

22. Mashiga F. Imai K, Souga T; A simple and sensitive assay of total serum bile acids. Clin Chim Acta 70:79-86, 1976

23. Osuga T, Mitamura F, Mashiga F, et al: Evaluation of fluorometrically estimated serum bile acids in liver disease. Clin Chim Acta $75: 81-90,1977$

24. Horst RL, Littledyke ET, Riley JL, et al: Quantitation of vitamin $D$ and its metabolites and their plasma concentration in five species of animals. Anal Biochem 16:189-203, 1981

25. Wiesner RH, LaRusso NF, Ludwig J, et al: Comparison of the clinicopathologic features of primary sclerosing cholangitis and primary biliary cirrhosis. Gastroenterology 88:108-114, 1985

26. Sedman AB, Klein GL, Heyman $M B$, et al: Bone and hepatic abnormalities associated with aluminum loading in piglets (Abstract). Clin Res 33:913A, 1985

27. DeLamirande E, Tuchweber B, Plaa GL: Hepatocellular membrane alteration as a possible cause of manganese-bilirubin-induced cholestasis. Biochem Pharmacol 30:2305-2312, 1981

28. Farrell MK, Gilster S, Balistreri WF: Serum bile acids: An early indicator of parenteral nutrition-associated liver disease. (Abstract) Gastroenterology 86:1074, 1984

29. Zahavi I, Shaffer EA, Gall DG: Total parenteral nutrition-associated cholestasis: Acute studies in infant and adult rabbits. J Pediatr Gastroenterol Nutr 4:622-627, 1985
30. Heyman MB. Ling V. Thaler MM: Effects of total parenteral nutrition (TPNi on biliay function in rapidly growing rats (Abstract). Pediatr Res 18:119A, 1984

31. Galle P. Giudicelli CP: Toxicite de l'aluminum pour l'hepatocyte. Localization ultrastructurale et microanalyse des depots. Nouv Presse 11:1123-1125. 1982

32. Verbueken AH. Van de Vyer FL. Van Grieken RE, et al: Ultrastructural localization of aluminum in patients with dialysis-associated osteomalacia. Clin Chem 30:763-768, 1984

33. Sewell RB. Barham SS. LaRusso N: Effect of chloroquine on the form and function of hepatocite lysosomes. Gastroenterology 85:1146-1153, 1983

34. Kovalchik MT, Kaehny WD, Jackson T, et al: Aluminum kinetics during hemodialysis. J Lab Clin Med 92:712-716, 1978

35. Klein GL, Ott SM, Alfrey AC, et al: Aluminum as a factor in the bone disease of long-term parenteral nutrition. Trans Assoc Am Phys 95:155-164, 1982

36. Horst RL, Littledyke ET: Comparison of plasma concentrations of vitamin $\mathrm{D}$ and its metabolites in young and aged domestic animals. Comp Biochem Physiol 73B:485-489, 1982

37. Whyte MP Haddad JG Jr, Walters DD, et al: Vitamin D bioavail ability: Serum 25-hydroxyvitamin D levels in man after oral, subcutaneous, intramuscular, and intravenous vitamin D administration. J Clin Endocrinol Metab 48:906-911, 1979

38. Bidlack WR, Brown RC, Meskin MS, et al: Effect of aluminum of the hepatic mixed function oxidase and drug metabolism. Drug Nutr Interact (in press)

39. Alfrey AC: Aluminum metabolism in uremia. Neurotoxicology $1: 43-53,1980$ 